\title{
Different male vs. female breeding periodicity helps mitigate offspring sex ratio skews in sea turtles
}

\author{
Graeme C. Hays ${ }^{1,2}{ }^{2}$, Antonios D. Mazaris ${ }^{3}$ and Gail Schofield ${ }^{1}$ \\ ${ }^{1}$ Centre for Integrative Ecology, School of Life and Environmental Sciences, Deakin University, Warrnambool, VIC, Australia \\ ${ }^{2}$ Department of Biosciences, Swansea University, Swansea, UK \\ ${ }^{3}$ Department of Ecology, School of Biology, Aristotle University of Thessaloniki, Thessaloniki, Greece
}

Edited by:

Rob Harcourt, Macquarie University,

Australia

\section{Reviewed by:}

Clive Reginald McMahon, University

of Tasmania, Australia

Ari Friedlaender, Oregon State

University, USA

\section{*Correspondence:}

Graeme C. Hays, Centre for

Integrative Ecology, School of Life

and Environmental Sciences, Deakin

University, Princes Hwy,

Warrnambool, VIC 3280, Australia

e-mail:g.hays@deakin.edu.au
The implications of climate change for global biodiversity may be profound with those species with little capacity for adaptation being thought to be particularly vulnerable to warming. A classic case of groups for concern are those animals exhibiting temperature-dependent sex-determination (TSD), such as sea turtles, where climate warming may produce single sex populations and hence extinction. We show that, globally, female biased hatchling sex ratios dominate sea turtle populations (exceeding $3: 1$ in $>50 \%$ records), which, at-a-glance, reiterates concerns for extinction. However, we also demonstrate that more frequent breeding by males, empirically shown by satellite tracking 23 individuals and supported by a generalized bio-energetic life history model, generates more balanced operational sex ratios (OSRs). Hence, concerns of increasingly skewed hatchling sex ratios and reduced population viability are less acute than previously thought for sea turtles. In fact, in some scenarios skewed hatchling sex ratios in groups with TSD may be adaptive to ensure optimum OSRs.

Keywords: skipped breeding, ectotherm, reptile, climate change, environmental sex determination, reproductive investment

\section{INTRODUCTION}

It is now widely acknowledged that climate change is producing profound alterations to ecosystems, including changes in abundance as well as shifts in distribution and phenology, with associated consequences for ecosystem services (Parmesan and Yohe, 2003). In some cases, the mechanistic link between climate and biological variables seems intuitive. For example, for marine species that have thermally controlled distributions, range changes over recent decades often correspond with the movement of isotherms (local climate velocities), with a general pattern for range expansion by warm water species and vice versa (Pinsky et al., 2013; Hinder et al., 2014). Arising from these studies, one of the concerns is that generally rising temperatures may negatively impact a number of species, with classic examples of species facing an uncertain future being those living at high altitudes (mountain tops) and at high latitudes, since both groups will experience declining (and possibly vanishing) habitat over future decades. In addition, climate change may have subtler, but equally profound, implications for other species whose available habitat is not negatively impacted. Changes in the seasonal timing of peak abundance may disrupt the trophic linkages in food webs and cause new trophic matches and mismatches (Edwards and Richardson, 2004).

Rising temperatures may not only disrupt the seasonal timing of breeding but also impact sex ratios, particularly for species with temperature dependent sex determination (TSD), such as many reptiles, with the sex that is produced at warmer temperatures becoming increasingly abundant until, ultimately, non-viable single sex populations may exist (e.g., Janzen, 1994; Mitchell and
Janzen, 2010; Mitchell et al., 2010). This scenario has been invoked as a possible cause for the extinction of dinosaurs (Miller et al., 2004) and has been repeatedly invoked for sea turtles, where many species or populations are under threat and where often existing incubation temperatures are leading to predominantly female skewed hatchling sex ratios (Mrosovsky et al., 1984; Mrosovsky and Provancha, 1992; Davenport, 1997; Hawkes et al., 2009; Poloczanska et al., 2009; Witt et al., 2010; Fuentes and Porter, 2013; but also see Katselidis et al., 2012).

It has recently been suggested that more frequent breeding by male turtles may help mitigate female skewed hatchling sex ratios by producing more balanced operational sex ratios (Hays et al., 2010; Wright et al., 2012; Laloë et al., 2014). Yet information on the biology of males and their breeding periodicity remains scarce, largely because they do not come ashore and so are difficult to study. Here, we provide the most comprehensive investigation to date of male vs. female breeding periodicity. First, we use 8 years of adult male and female satellite tracking data to directly measure sex differences in breeding periodicity at a major rookery. This is a unique data-set in terms of long-term tracking of both sexes. Second, we develop a generic life-history model, based around the rates of acquisition and use of body reserves when at foraging sites vs. breeding sites, to consider if the empirical findings from satellite tracking on sex biases in breeding periodicity are likely to apply broadly across sea turtles species and populations. Third, we compile hatchling sex ratios reported across the globe to assess whether female skews reported for some populations and regions apply more broadly. Hence, we critically consider whether male breeding periodicity will likely 
lead operational sex ratios to become closer to parity than hatchling sex ratios and, hence, if concerns of increasingly skewed hatchling sex ratios are less acute than previously thought for sea turtles.

\section{MATERIALS AND METHODS EMPIRICAL OBSERVATIONS OF BREEDING PERIODICITY: SATELLITE TRACKING}

Between 2004 and 2012 our research group and other groups have equipped a large number of breeding adult male and female turtles with satellite transmitters on Zakynthos Island, Greece ( $n=82$ individuals; $37^{\circ} 43^{\prime} \mathrm{N}, 20^{\circ} 52^{\prime} \mathrm{E}$ ), which is the largest loggerhead sea turtle (Caretta caretta) rookery in the Mediterranean. Some of these results ( $n=75$ adult males and females) have been described previously, and have been used to identify patterns of movement and area use on breeding and foraging grounds (Hays et al., 2010; Zbinden et al., 2011; for overview see: Schofield et al., 2013a,b). In addition, a further seven males were tracked in 2012, for which data have not been previously published. For the first three male turtles that we tracked for at least 1 year (2008-2009), we assessed whether individuals bred in successive years (Hays et al., 2010). Here, we extend this analysis of breeding periodicity to include all the turtles (both males and females) that have been tracked for sufficiently long periods to assess whether they return to the breeding area to reproduce in successive years. In brief, we caught male turtles at sea in early May (before the onset of female nesting activity) close the nesting beaches, and attached satellite tags with quick setting epoxy (for detailed description see Schofield et al., 2013a,b). Female turtles were either captured at sea in May (before the onset of nesting activity) or equipped while they were ashore nesting (between late May and early August; for detailed descriptions see Zbinden et al., 2011; Schofield et al., 2013a,b). Several models of satellite transmitters were used by the various research groups (see Supplementary Table S1 for the turtles used in this study, and (Schofield et al., 2013a,b) for a list of units attached to all individuals in all years). Units provided either Argos quality or GPS quality locations relayed via the Argos satellite system or the mobile phone network.

Broadly speaking, we assessed if individuals bred in successive years by considering the results from transmitters that were still functioning 1 year after attachment. This general pattern of looking for breeding in successive years was fine-tuned as follows based on differences in the biology of males and females. The peak mating period for loggerhead turtles at Laganas Bay, Zakynthos, is mid-April and the latest documented arrival of a breeding male is 2 May (Schofield et al., 2013b). So, male turtles were recorded as breeding in successive years if they had returned to Laganas Bay, Zakynthos by mid-May of the year following tag attachment. If they were still being tracked and had not returned to the breeding area, they were defined as not breeding in successive years. This is a robust distinction because a central component of sea turtle biology is that turtles travel from distant foraging grounds to breed. Resident males were confirmed to be participating in breeding activity based on direct observations of reproductive behaviors (examples are presented in Schofield et al., 2006). Only females that were tracked until at least 1 July of the year following transmitter attachment were included in the analysis, which is after the latest date that a female has been recorded to return to breed (8 June) and/or initiate nesting (25 June) on Zakynthos (Schofield et al., 2013b). Females returning to the breeding area within this time were recorded as breeding in successive years with nesting often confirmed by visual observations, although beach patrols were insufficient to observe the turtle responsible for every nest. As with males, migration from distant foraging grounds to breed at nesting areas is a key feature central tenant of sea turtle biology.

To test the hypothesis that females return to breed with the same probability as males, we performed a permutation test. Based on data collected from males, we defined the probability of returning every successive year. Next, a Bernoulli random value was drawn according to this probability, to generate return patterns for a set of eight individuals, equal to the number of females for which satellite data are available. The processes involved 9999 permutations. To examine whether there was a significant difference in the migration distance undertaken by male turtles that returned to breed over successive years and those that remained on the feeding grounds, we used a randomization process that allowed us to extract equal samples of individuals from the our sample, obtaining the level of significance after 9999 permutations.

\section{MECHANISTIC MODEL OF BREEDING PERIODICITY}

To predict the relative breeding periodicities of male and female sea turtles, we developed a model built around the two fundamental differences in their breeding life history: first that females invest energy in clutches of eggs while males do not; second that males have a much shorter period of residence on the breeding grounds than females, so they arrive back at their foraging grounds earlier and, hence, start to re-build their energy reserves sooner than females (Schofield et al., 2013a,b). It is widely thought that turtles on the breeding grounds feed less than those on the foraging grounds, sometimes fasting completely while breeding (e.g., Bjorndal, 1982). By incorporating these two fundamental differences between males and females, rather than detailed rookery-specific details, we developed a model that is likely to be generic across sea turtle populations. We used literature values for the expected duration of residence on the breeding grounds, migration between breeding and foraging areas, and energetic investment in clutches, to quantify the expected trajectories of body condition of males vs. females over complete foraging and breeding cycles which may span several years. This conceptual framework for our model is appropriate given than adult turtles grow minimally once they attain sexual maturity (Broderick et al., 2003).

\section{GLOBAL PATTERNS OF HATCHLING SEX RATIOS}

We used the published literature to assemble a database on hatchling sex ratios for sea turtle breeding sites across the globe. Data were found for six species: the green turtle (Chelonia mydas), hawksbill turtle (Eretmochelys imbricata), loggerhead turtle (Caretta caretta), leatherback turtles (Dermochelys coriacea), flatback turtle (Natator depressus), and olive ridley turtle (Lepidochelys olivacea). Initially, we searched the Thomson Reuters ISI Web of Science database for papers that included the 
terms "sea turtle" and "sex ratio" in the topic field, which includes the title, abstract, keywords, and Keywords Plus (i.e., words that frequently appear in the titles of the articles cited within a publication). We excluded all conference proceedings and theses. To locate additional articles that might not have been identified by the initial search, we also checked the reference lists of relevant papers based on the pre-defined terminology. We only included studies that presented sex ratio estimates for hatchlings (i.e., on emergence from nests at the nesting beaches). In these studies, the sex ratios of hatchlings were either measured directly, which involves sacrificing hatchlings and the histological examination of the gonads, and/or were predicted by in situ measurements of sand temperatures on the nesting beaches combined with established relationships between sand temperature and hatchling sex ratio.

\section{RESULTS \\ EMPIRICAL OBSERVATIONS OF BREEDING PERIODICITY}

Seventeen satellite tracks of 15 males and eight satellite tracks of unique females met the required time-scale criteria of this study. Individuals migrated to widely dispersed sites throughout the entire Mediterranean basin. Overall, in $76 \%$ of instances (13 of 17 tracks), males returned to the breeding area within 1 year, compared to $0 \%$ ( 0 of 8 tracks) of females (Figures 1A,B, Supplementary Table S1), clearly highlighting the difference in return rates between males and females. All males that were resident to Zakynthos/Peleponesse $(n=6$ tracks) or migrated to foraging grounds north of Zakynthos ( $n=4$ tracks) returned to breed annually. In contrast, of those that migrated to foraging grounds south of Zakynthos off the coast of Africa ( $n=7$ tracks), three returned to breed after 1 year, while the other four remained at the foraging grounds. Of note, one male that was tracked in two separate years (2010 and 2013) to southerly foraging grounds (Gulf of Gabes, Tunisia) returned to breed after 2 years and 1 year, respectively. Of the tracked females, six and two individuals migrated to foraging grounds north and south of Zakynthos, respectively. Hence, females did not exhibit annual return rates, despite frequenting similar foraging grounds to those of males that did return to breed annually (Figures 1C,D).

Assuming that the observed probability of male return to the breeding area over successive years was equal to 0.764 , our analyses revealed a significantly lower return rate for females $(p<$ 0.001 ). Our permutation test further demonstrated that for male turtles the average distance between the breeding and foraging areas was significantly lower for those individuals breeding in successive years than for those that did not breed in successive years $(p<0.001)$.

\section{MECHANISTIC MODEL FOR CLIMATE IMPACT ON BREEDING}

Both male and female turtles tend to travel between disparate breeding and foraging sites. They accumulate energy reserves on their foraging grounds and use these reserves to sustain their migrations to and from, and residence at, breeding areas.

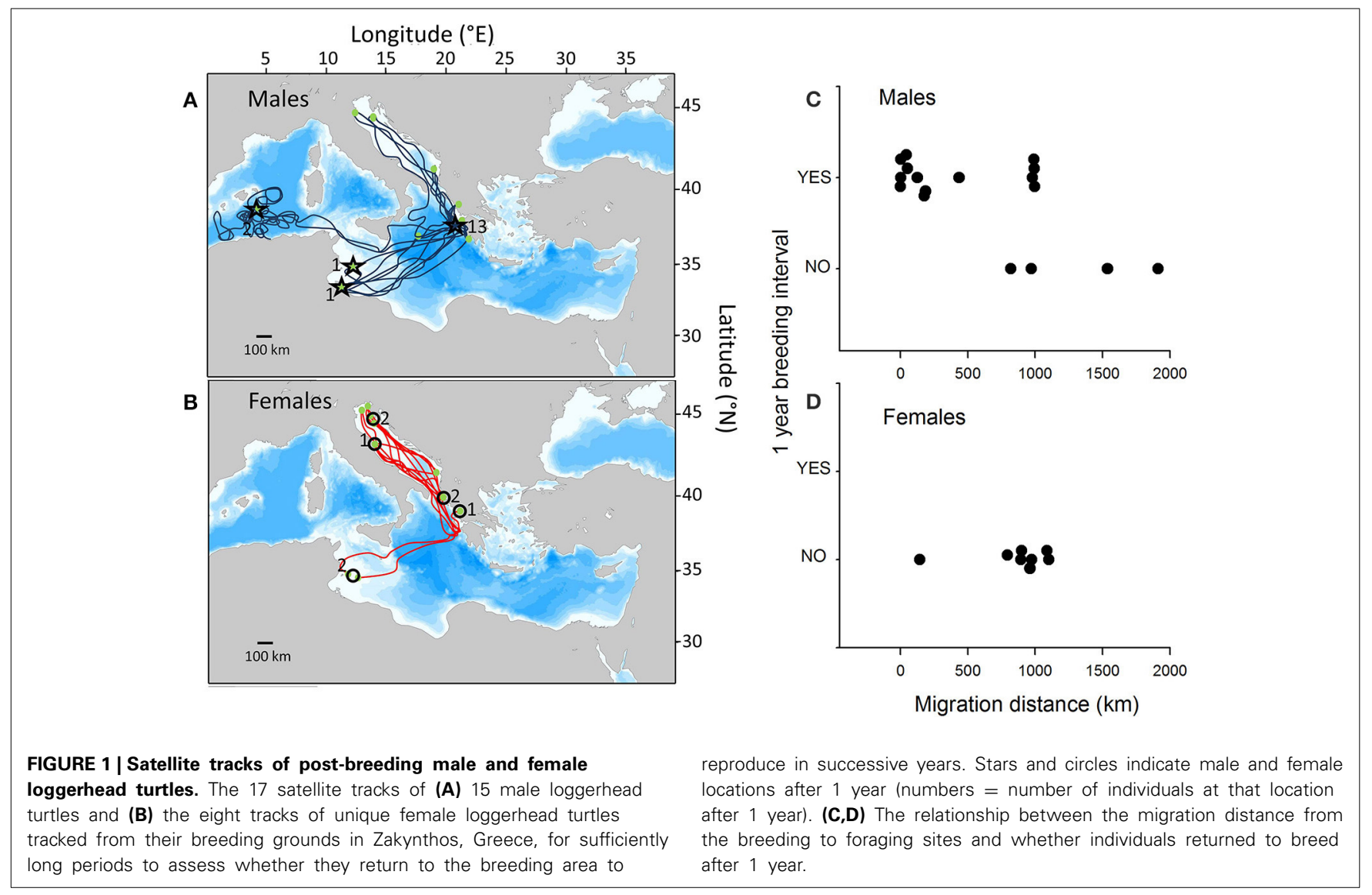


While they share this common feature of long-distance migration, females may take longer to accumulate sufficient energy resources to sustain a breeding migration for two reasons: (i) first since females invest energy in producing eggs and excavating nests, their rate of loss of body condition when away from the foraging grounds is likely to be higher than for males and (ii) second females remain at the breeding area after the mating season to lay clutches of eggs, and are therefore away from the foraging grounds for longer than males.

The periodicity of breeding in sea turtles may be viewed as an alternation of increasing vs. decreasing body condition associated with time spent at, vs. away from, the foraging grounds. We modeled why individuals do not breed every year by conceptualizing their change in body condition over a breeding cycle as (i) a gradient of increasing body condition when on the foraging grounds vs. (ii) a general gradient of decreasing in body condition when away from the foraging grounds.

The time an individual spends away from the foraging grounds $\left(\mathrm{T}_{\text {away }}\right)$ is the time spent migrating to the breeding grounds, plus time spent at the breeding grounds, plus time spent migrating back to the foraging grounds. Let us denote the mean gradient for the loss in body condition during this time as $\mathrm{G}_{\text {away. }}$. Let us denote time spent at the foraging grounds prior to the next breeding year as $\mathrm{T}_{\text {home }}$ and the mean rate of increase in body condition during this time as Ghome. Then if we assume that the decision to breed is based on an individual attaining a threshold body condition, then:

$$
\mathrm{T}_{\text {away }} \times \mathrm{G}_{\text {away }}=\mathrm{T}_{\text {home }} \times \mathrm{G}_{\text {home }}
$$

We may realistically parameterize $\mathrm{T}_{\text {away }}$ and $\mathrm{T}_{\text {home }}$ and then solve this equation for the relative values of $G_{\text {away }} v s$. $G_{\text {home }}$. For example, if we consider a male turtle, let us assume first that the time spent away from the foraging grounds is 90 days. This is a reasonable value to use. For example, while male migration distances are variable, we might consider 15 days migrating to the breeding grounds (at a speed of travel of $50 \mathrm{~km}$.day ${ }^{-1}$ this equates to a migration distance of $750 \mathrm{~km}$ ), 60 days at the breeding grounds, and 15 days migrating back to the foraging grounds, i.e., 90 days ( 0.25 year) away from the foraging grounds. While these are reasonable values to assume as a starting point (Hays and Scott, 2013; Schofield et al., 2013b), we will show later that the key conclusions from the model are relatively insensitive to the exact values used. Hence, if an individual male breeds every year (i.e., $\mathrm{T}_{\text {away }}+\mathrm{T}_{\text {home }}=1$ year), then Equation (1) becomes:

$$
0.25 \times \mathrm{G}_{\text {away }}=0.75 \times \mathrm{G}_{\text {home }}
$$

Therefore : $\mathrm{G}_{\text {away }}=3 \mathrm{G}_{\text {home }}$

i.e., the individual loses body condition 3 times faster than it gains body condition. Similarly if a male turtle breeds every 2 years, then:

$$
0.25 \times \mathrm{G}_{\text {away }}=1.75 \times \mathrm{G}_{\text {home }}
$$

Therefore : $\mathrm{G}_{\text {away }}=7 \mathrm{G}_{\text {home }}$
If a male turtle breeds every 3 years, then:

$$
0.25 \times \mathrm{G}_{\text {away }}=2.75 \times \mathrm{G}_{\text {home }}
$$

Therefore : $\quad \mathrm{G}_{\text {away }}=11 \mathrm{G}_{\text {home }}$

If we consider the situation for female turtles, the key differences with males are their investment in clutches and their increased time spent away from the foraging grounds. The energy content of a clutch of sea turtle eggs has been estimated to be equal approximately the energy expended over 15 days (Bjorndal, 1982; Hays et al., 2000). If we assume that a female produces three clutches over a 45 day period ( 0.125 year), then this additional investment in breeding by a female can be added to the energy balance equation:

$$
\begin{aligned}
& \text { Energy spent in time away from }+ \text { Investment in eggs } \\
& \quad=\text { Energy gained on foraging grounds foraging }
\end{aligned}
$$

We may again solve this energy balance equation using the relative values for $G_{\text {away }}$ vs. $G_{\text {home }}$ for male turtles with the addition of a term for the investment in eggs. For example, in a situation where a male turtle is breeding every 2 years $\left(G_{\text {away }}=7 G_{\text {home }}\right)$, then for a female we have:

$$
\begin{gathered}
\left((0.25+0.125) \times \mathrm{G}_{\text {away }}\right)+\left(0.125 \times \mathrm{G}_{\text {away }}\right)=\mathrm{T}_{\text {home }} \times \mathrm{G}_{\text {home }} \\
(0.375 \times 7)+(0.125 \times 7)=\mathrm{T}_{\text {home }}
\end{gathered}
$$

Therefore : $\quad \mathrm{T}_{\text {home }}=3.5$ years

So, the interval between breeding seasons must then be the nearest integer higher that $\mathrm{T}_{\text {away }}+\mathrm{T}_{\text {home }}$, i.e., $0.375+3.5$. So, the breeding interval for a female in this scenario is 4 years, i.e., double the length of that required for males. Similarly, solving the equation for the breeding periodicity of females when the male breeding interval is 1 year, produces:

$$
\begin{gathered}
(0.375 \times 3)+(0.125 \times 3)=\mathrm{T}_{\text {home }} \\
\mathrm{T}_{\text {home }}=1.5 \text { years and breeding interval is } 2 \text { years }
\end{gathered}
$$

When the male breeding interval is 3 years :

$$
\begin{gathered}
(0.375 \times 11)+(0.125 \times 11)=\mathrm{T}_{\text {home }} \\
\mathrm{T}_{\text {home }}=5.5 \text { years and breeding interval is } 6 \text { years }
\end{gathered}
$$

We may extend this analysis to consider how breeding periodicity will change given different values for the time spent in migration, i.e., different amounts of time that both males and females remain away from the foraging grounds during a breeding season (Figure 2). These simulations show importantly how (i) across a range of breeding interval for males and different durations of migration (i.e., varying the length of residence away from the foraging grounds in a breeding year), the interval between breeding seasons for females is always longer than for males (Figure 2A); and (ii) this relative interval between female vs. male breeding periodicity is higher when the migration time is shorter (Figure 2B). 


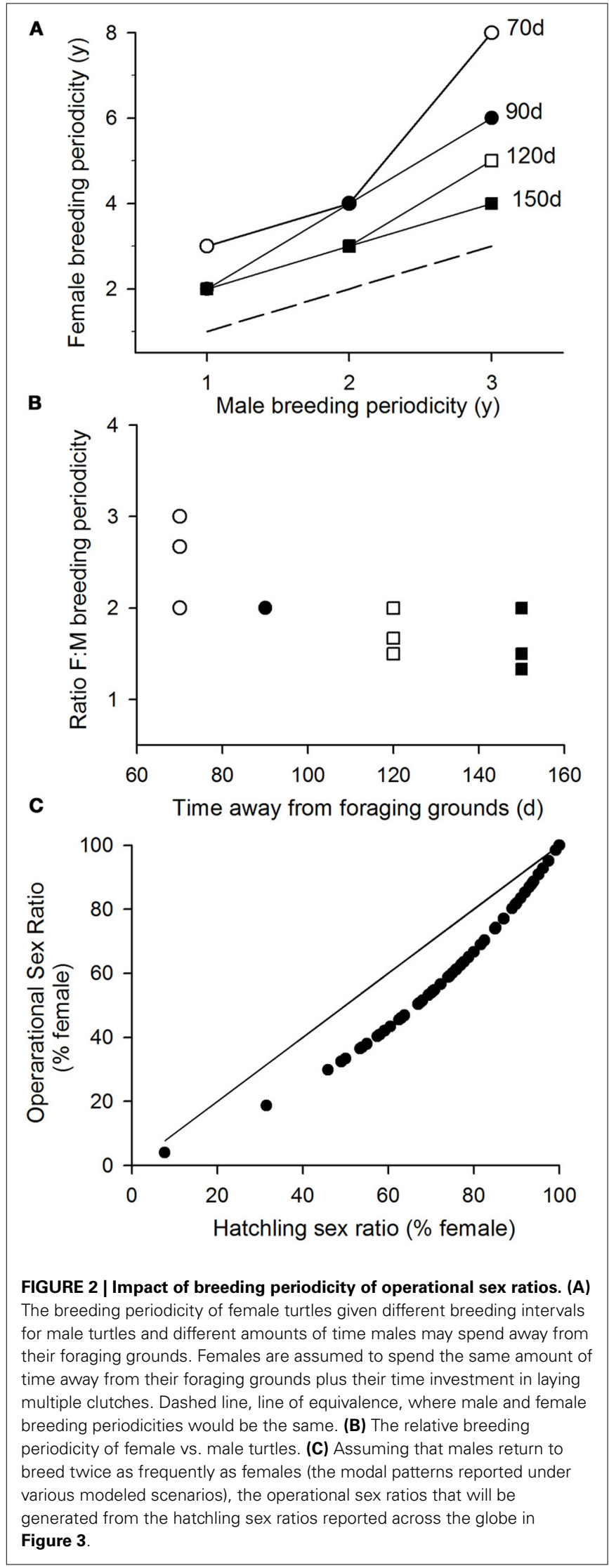

In these considerations, the male breeding periodicity equals the gradient of the increase in body condition when on the foraging grounds, i.e., is a measure of foraging success. So, if climate influences foraging success (and hence male breeding periodicity), our results show how there will be the same effect on female breeding periodicity, i.e., male and female breeding periodicity will co-vary. The model most typically predicts that males will breed twice as often as females. So we may use this modal pattern to estimate the operational sex ratios that will be generated from the hatchling sex ratios reported across the globe (Figure 2C). This analysis shows that around the world OSRs tend to be more balanced than hatchling sex ratios. For example, the hatchling sex ratio of $74 \%$ females recorded in Taiwan for green turtles translates to an OSR of $58.7 \%$ females and likewise these values for green turtles nesting in Costa Rica will be 67 and 54\%, respectively.

\section{GLOBAL PATTERNS OF HATCHLING SEX RATIOS}

In total, we located 46 articles that provided estimates of hatchling sex ratio for global sea turtle nesting populations, over a range of breeding seasons (Figure 3, Supplementary Table S2). A male biased sex ratio was reported in just four records at three distinct breeding areas. However, for one of these breeding populations (i.e., leatherback nesting in Suriname), a subsequent study revealed an inverse sex ratio pattern. Overall, a highly skewed sex ratio was detected with more than half of the records indicating a female to male ratio that was higher than 3:1, and only two studies supporting a balanced sex ratio. It should be noted that high inter-annual variability was also obtained for some cases (e.g., the sex ratio of green turtles nesting in Bijagos Archipelago in Guinea-Bissau was estimated to $85 \%$ female during the 2008 nesting period and dropped to $55 \%$ in 2009). Similarly, spatial variability was also detected with neighboring nesting sites producing different hatchling sex ratios, for example the sex ratio of green turtles nesting at various sites on Ascension Island differed appreciably.

\section{DISCUSSION}

We provide comprehensive evidence that male sea turtles breed more frequently than females and, hence, female skewed hatchling sex ratios will translate into more balanced operational sex ratios. Further, our analysis of sea turtle hatchling sex ratios around the globe shows strong evidence for a generally highly female skewed hatchling sex ratio for six of the seven sea turtle species, for which data were available. Set against this backdrop, the adaptive significance of TSD in reptiles, and resulting skewed hatchling sex ratios, has remained enigmatic for several decades (Mrosovsky et al., 1984; Bull and Charnov, 1989; Warner and Shine, 2008; Mitchell et al., 2010). One possibility is that these hatchling sex ratios are not beneficial but are simply an unavoidable, maladaptive, consequence of TSD and current environmental temperatures (Mrosovsky, 1994). Under this scenario, populations with highly skewed female sex ratios may persist because sea turtles are polyandrous with males able to breed with many females (e.g., Lee and Hays, 2004). Females store sperm to fertilize the eggs they lay within several clutches sometimes 


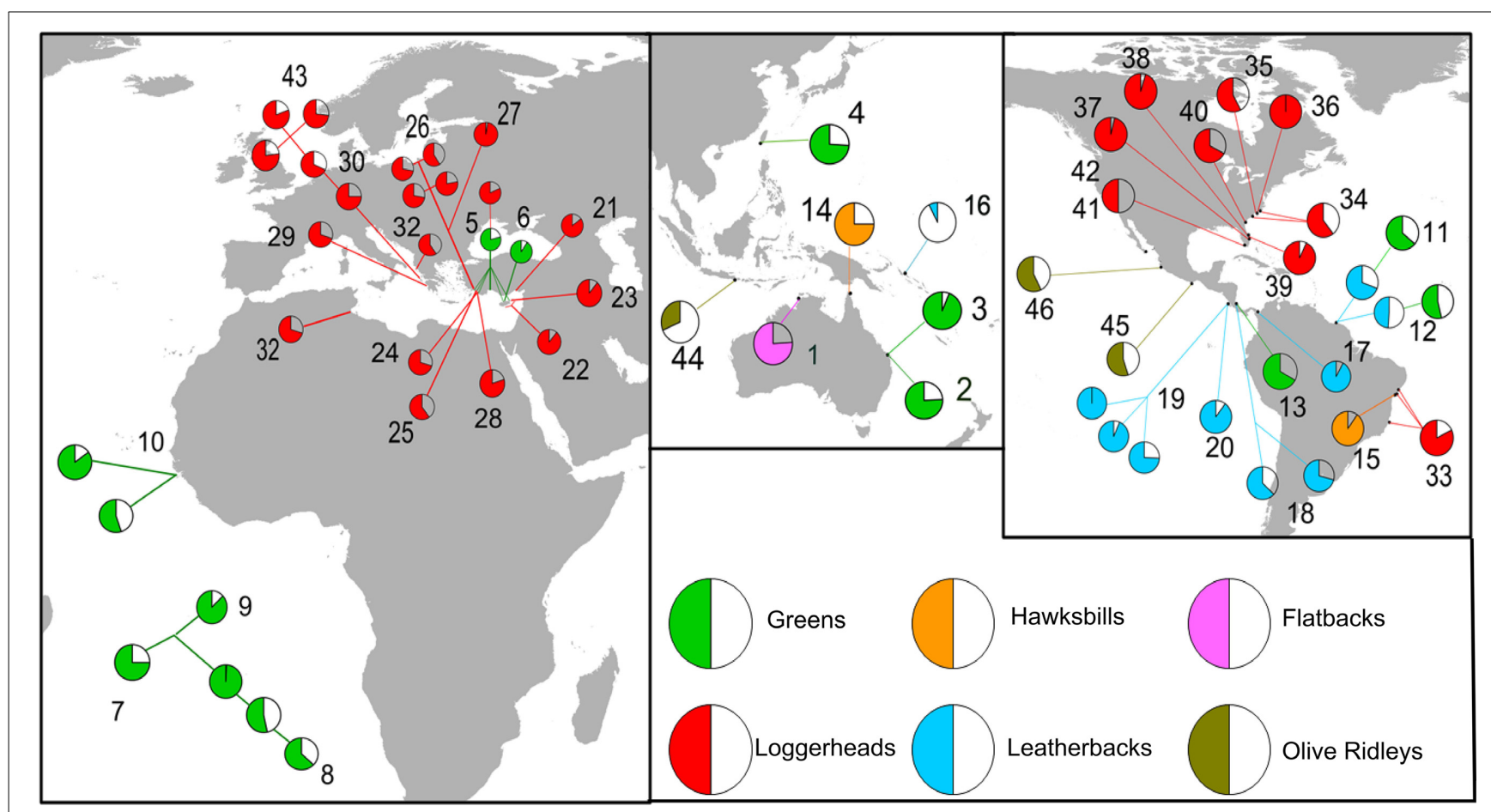

FIGURE 3 | Hatchling sex ratios recorded for sea turtle populations around the globe. The estimated proportion of females are presented as the filled slices of the pie charts; different species are presented under different colors. Numbers indicate source literature presented in Supplementary Table S2.

produced many weeks or even months after the males have left the breeding grounds. So, a few male turtles may potentially fertilize the eggs of many females. Thus, in theory, female skewed operational sex ratios would still result in fertile eggs being laid. Yet, there may be other consequences of only small proportion of males on the breeding grounds, such as the loss of genetic diversity (Mitchell et al., 2010). Hence, OSRs that are not so heavily female skewed might be expected to increase population viability.

A second possibility is that generally female skewed hatchling sex ratios are actually adaptive. For example, the behavioral polymorphism in nest site selection, which may have a genetic basis (Kamel and Mrosovsky, 2005), and the conservatism of pivotal temperatures (Mrosovsky, 1994) might be indicative of adaptive mechanisms toward ensuring optimum sex ratios. Furthermore, although there is current warming across the globe, temperatures are generally only a few fractions of a degree above long-term records (Mann et al., 2008). Thus, current hatchling sex ratio biases may have existed for centuries. In this context, it may be that the preferences of nesting females and pivotal temperatures have evolved toward producing an optimum operational sex ratio, even if this means that hatchling sex ratios are unbalanced. Our findings lend some support for this concept of adaptively skewed hatchling sex ratios in sea turtles and lend further support to previous conclusions with lizards, another group with TSD, that TSD may be adaptive in certain situations (Warner and Shine, 2008; Pen et al., 2010).

In absolute terms, our calculations suggest that the impact of differential male-female breeding intervals on operational sex ratios becomes most important at intermediate sex ratios. For example, with a hatchling sex ratio of $68.0 \%$ female, our calculations suggest the operational sex ratio will be $51.5 \%$ female, a $16.5 \%$ difference; but at a hatchling sex ratio of $97.5 \%$ female then the OSR will be $95.1 \%$ female, a difference of only $2.4 \%$. These calculations suggest that increased male breeding periodicity might have limited impact at extremely female biased hatchling sex ratios. However, contrary to this argument, it is notable that some very large populations have a high female hatchling skew. For example, many tens of thousands of sea turtles nest on beaches on the Atlantic coast of Florida and, yet, beaches in this area generally produce $>90 \%$ female hatchlings (Mrosovsky and Provancha, 1992). The fact that such large populations exist suggests that population viability may not be seriously compromised, even at these extreme sex ratio skews, possibly because a few males in the population breed often and are able to fertilize the clutches of many females.

While our satellite tracking results from males and females provide strong empirical evidence for a disparity in breeding intervals, there is little comparable data from other sites, because almost exclusively tracking studies with adult turtles focus on females, which are much easier to equip as they come ashore to nest. However, male leatherback turtles (Dermochelys coriacea) tracked from their foraging grounds in the Atlantic return to breed more frequently than females (James et al., 2005). In addition to the tracking results, there is one equally strong empirical data-set for male vs. female breeding periodicities. In a unique and extensive study, Limpus et al. (2005) captured adult male and female green turtles on their foraging grounds around the Great 
Barrier Reef area (Australia) and then used laparoscopy to identify those individuals which would breed in a particular year vs. those that would remain on their foraging grounds. Their results, again, showed that males breed more frequently than females and this pattern was maintained across years where there were marked differences in the forging conditions. These findings for a second species (green turtles vs. our tracking of loggerhead turtles) point to the generality of this difference in male vs. female breeding periodicity, a conclusion that is further strengthened by our lifehistory modeling. Interestingly we found that about one-third of males tend to remain resident at the breeding grounds throughout the year, whereas females did not. This phenomenon has been noted before for this site (Schofield et al., 2010), and may be beneficial to males as it maximizes their chances of intercepting and mating with females upon their arrival to breed and, hence, allows males to father more offspring. However, even when males migrated to distant foraging sites, they had a greater tendency to return to breed after 1 year compared to females. Elsewhere in the world, it has also been shown that male turtles tend to remain resident close to the breeding grounds more often than females (van Dam et al., 2008; Arendt et al., 2012), suggesting that this sex-specific migration tendency may be a common feature for sea turtles.

We took the approach of identifying the key differences in the time budget of males vs. females associated with breeding; thus, our model did not need any estimates of the actual metabolic rates of free-living adult turtles, which are generally lacking (Southwood and Avens, 2010). In this way, we attempted to make the outputs of our model as robust as possible. We made realistic estimates of the length of time that males and females may be away from the foraging grounds based on the reported distances of migration (e.g., Hays and Scott, 2013), arrival and departure times from breeding grounds (Schofield et al., 2013b) and the measured clutch frequency of females (e.g., Bjorndal, 1982). These time-budgets could be modified as more empirical evidence accrues. For example there is recent evidence that the traditional method of recording the clutch frequency for females, namely observing flipper tagged individuals as they nest across a season, may underestimate their true clutch frequency (Tucker, 2010; Weber et al., 2013). Similarly, the period of residence at the breeding grounds for male turtles is generally not well known, with the usual assumption being that males are only observed during the mating season and then are not seen during the nesting season, as they have departed to their foraging grounds (Godley et al., 2002; Schofield et al., 2013b). Furthermore, it might be possible to assess how the quality of the foraging habitat impacts rates of energy acquisition and hence breeding intervals (Broderick et al., 2001; Heithaus et al., 2009, 2014). However, the exact parameterization of both these values for female and male residence at the breeding grounds are relatively unimportant, as they are both essentially considered in out sensitivity analysis when we assume different lengths of time away from the foraging grounds. Regardless of these lengths of time that are assumed, we reach the same overarching conclusion: the interval between breeding years in males will be less than in females. In this sense, sea turtles seem to parallel some birds, where the larger investment in reproduction by females may lead to skipped breeding in subsequent years (Chastel et al., 1995; Nevoux et al., 2007).

In some cases (e.g., male turtles breeding in Greece), we now know from direct satellite tracking that most males breed in successive years and most females do not. At other sites (e.g., where migration distance is longer or the rate of energy gain on the foraging grounds in slower), then our results show that males may tend to only breed every 2 or 3 years, but likewise the corresponding breeding interval for females will be longer still. This situation has been reported for green turtles in Australia (Limpus et al., 2005). Similarly, we show that the impact of climate variability, by impacting foraging conditions, will impact both males and females: poor foraging conditions will lengthen the breeding interval for both sexes and vice versa, a result that has again been show empirically (Limpus et al., 2005). So, the model is robust regardless of assumptions for the length of time that turtles are away from their foraging grounds or their foraging conditions. Hence, the key conclusion, that in general, across different species, the interval between breeding seasons will be lower for males than for females, is broadly applicable.

There is debate about when wildlife management intervention may be needed to mitigate impacts of climate change, such as captive breeding and population relocations, to prevent extinction for species whose range is decreasing. In the context of sea turtles, one debate concerns whether artificial cooling of nests is needed now, or in the near future, to ensure that hatchling sex ratios are not too female biased (Patino-Martinez et al., 2012; Wood et al., 2013). Our evidence suggests that, in many cases, such management intervention is not going to be needed for some time, with skewed hatchling sex ratios resulting in more balanced adult sex ratios on the breeding grounds. Furthermore, turtles may have had to respond previously to climate change and may show adaptations that help them mitigate warming temperatures, such as phenological changes in the seasonal timing of nesting (e.g., Hawkes et al., 2009; Poloczanska et al., 2009). Further measurements and long-term monitoring of hatchling sex ratios may help to refine estimates of hatchling sex ratios skews across sites and allow more informed predictions of climate change impacts for future sex ratios (e.g., Laloë et al., 2014). Nevertheless, while there may be many profound ecological and socio-economic impacts of global warming, our empirical and modeling results indicate that the immediate impacts of warming on sex ratio skews in sea turtles may not be as dire as sometimes feared. While we show that female skewed hatchling sex ratios dominate globally, we provide strong evidence that a general feature for sea turtles is that the interval between breeding seasons for males will be shorter than for females and, hence, skewed female hatchling sex ratios will result in more balanced operational sex ratios.

\section{AUTHOR CONTRIBUTIONS}

Graeme C. Hays and Gail Schofield conceived the study and implemented the fieldwork. Antonios D. Mazaris assembled the hatchling sex ratio data-base and ran the permutation analyses. Gail Schofield assembled the tracking data. Graeme C. Hays generated the life history model. Graeme C. Hays led the writing with input from all authors. 


\section{ACKNOWLEDGMENTS}

We thank the National Marine Park of Zakynthos (NMPZ) for the permission to conduct this research, and the many people who provided assistance with in-water capture of turtles. All work was approved by the Swansea University Animal Welfare and Ethical Review Process Group.

\section{SUPPLEMENTARY MATERIAL}

The Supplementary Material for this article can be found online at: http://www.frontiersin.org/journal/10.3389/fmars. 2014.00043/abstract

\section{REFERENCES}

Arendt, M. D., Segars, A. L., Byrd, J. I., Boynton, J., Whitaker, J. D., Parker, L., et al. (2012). Distributional patterns of adult male loggerhead sea turtles (Caretta caretta) in the vicinity of Cape Canaveral, Florida, USA during and after a major annual breeding aggregation. Mar. Biol. 159, 101-112. doi: 10.1007/s00227-011-1793-5

Bjorndal, K. A. (1982). "The consequences of herbivory for the life history pattern of the Carribean green turtles, Chelonia mydas," in Biology and Conservation of Sea Turtles, ed K. A. Bjorndal (Washington, DC: Smithsonian Institution Press), 111-116.

Broderick, A. C., Glen, F., Godley, B. J., and Hays, G. C. (2003). Variation in reproductive output of marine turtles. J. Exp. Mar. Biol. Ecol. 288, 95-109. doi: 10.1016/S0022-0981(03)00003-0

Broderick, A. C., Godley, B. J., and Hays, G. C. (2001). Trophic status drives interannual variability in nesting numbers of marine turtles. Proc. Biol. Sci. 268, 1481-1487. doi: 10.1098/rspb.2001.1695

Bull, J. J., and Charnov, E. L. (1989). Enigmatic reptilian sex ratios. Evolution 43, 1561-1566. doi: 10.2307/2409470

Chastel, O., Weimerskirch, H., and Jouventin, P. (1995). Influence of body condition on reproductive decision and reproductive success in the blue petrel. Auk 112, 964-972. doi: 10.2307/4089027

Davenport, J. (1997). Temperature and the life-history strategies of sea turtles. J. Therm. Biol. 22, 479-488. doi: 10.1016/S0306-4565(97)00066-1

Edwards, M., and Richardson, A. J. (2004). The impact of climate change on the phenology of the plankton community and trophic mismatch. Nature 430, 881-884. doi: 10.1038/nature02808

Fuentes, M. M. P. B., and Porter, W. P. (2013). Using a microclimate model to evaluate impacts of climate change on sea turtles. Ecol. Model. 251, 150-157. doi: 10.1016/j.ecolmodel.2012.12.020

Godley, B. J., Broderick, A. C., Frauenstein, R., Glen, F., and Hays, G. C. (2002). Reproductive seasonality and sexual dimorphism in green turtles. Mar. Ecol. Prog. Ser. 226, 125-133. doi: 10.3354/meps226125

Hawkes, L. A., Broderick, A. C., Godfrey, M. H., and Godley, B. J. (2009). Climate change and marine turtles. Endang. Spec. Res. 7, 137-154. doi: 10.3354/esr00198

Hays, G. C., Adams, C. R., Broderick, A. C., Godley, B. J., Lucas, D. J., Metcalfe, J. D., et al. (2000). The diving behaviour of green turtles at Ascension Island. Anim. Behav. 59, 577-586. doi: 10.1006/anbe.1999.1326

Hays, G. C., Fossette, S., Katselidis, K. A., Schofield, G., and Gravenor, M. B. (2010). Breeding periodicity for male sea turtles, operational sex ratios, and implications in the face of climate change. Conserv. Biol. 24, 1636-1643. doi: 10.1111/j. 1523-1739.2010.01531.x

Hays, G. C., and Scott, R. (2013). Global patterns for upper ceilings on migration distance in sea turtles and comparisons with fish, birds and mammals. Funct. Ecol. 27, 748-756. doi: 10.1111/1365-2435.12073

Heithaus, M. R., Alcoverro, T., Arthur, R., Burkholder, D. A., Coates, K. A., Christianen, M. J. A., et al. (2014). Seagrasses in the age of sea turtle conservation and shark overfishing. Front. Mar. Sci. 1:28. doi: 10.3389/fmars.2014. 00028

Heithaus, M. R., Wirsing, A. J., Burkholder, D., Thomson, J., and Dill, L. M. (2009). Towards a predictive framework for predator risk effects: the interaction of landscape features and prey escape tactics. J. Anim. Ecol. 78, 556-562. doi: 10.1111/j.1365-2656.2008.01512.x

Hinder, S. L., Gravenor, M. B., Edwards, M., Ostle, C., Bodger, O. G., Lee, P. L. M., et al. (2014). Multi-decadal range changes vs. thermal adaptation for north east
Atlantic oceanic copepods in the face of climate change. Glob. Chang. Biol. 20, 140-146. doi: 10.1111/gcb.12387

James, M. C., Eckert, S. A., and Myers, R. A. (2005). Migratory and reproductive movements of male leatherback turtles (Dermochelys coriacea). Mar. Biol. 147, 845-853. doi: 10.1007/s00227-005-1581-1

Janzen, F. I. (1994). Climate change and temperature-dependent sex determination in reptiles. Proc. Natl. Acad. Sci. U.S.A. 91, 7487-7490. doi: 10.1073/pnas.91. 16.7487

Kamel, S. J., and Mrosovsky, N. (2005). Repeatability of nesting preferences in the hawksbill sea turtles (Eretmochelys imbricata) and their fitness consequences. Anim. Behav. 70, 819-828. doi: 10.1016/j.anbehav.2005.01.006

Katselidis, K. A., Schofield, G., Dimopoulos, P., Stamou, G. N., and Pantis, J. D. (2012). Females first? Past, present and future variability in offspring sexratio at a temperate sea turtle breeding area. Anim. Conserv. 15, 508-518. doi: 10.1111/j.1469-1795.2012.00543.x

Laloë, J.-O., Cozens, J., Renom, B., Taxonera, A., and Hays, G. C. (2014). Effects of rising temperature on the viability of an important sea turtle rookery. Nat. Clim. Change 4, 513-518. doi: 10.1038/nclimate2236

Lee, P. L. M., and Hays, G. C. (2004). Polyandry in a marine turtle: females make the best of a bad job. Proc. Natl. Acad. Sci. U.S.A. 101, 6530-6535. doi: 10.1073/pnas.0307982101

Limpus, C. J., Limpus, D. J., Arthur, K. E., and Parmenter, C. J. (2005). Monitoring Green Turtle Population Dynamics in Shoalwater Bay 2000-2004. Townsville, QLD: Research Publication Great Barrier Reef Marine Park Authority.

Mann, M. E., Zhang, Z., Hughes, M. K., Bradley, R. S., Miller, S. K., Rutherford, S., et al. (2008). Proxy-based reconstructions of hemispheric and global surface temperature variations over the past two millennia. Proc. Natl. Acad. Sci. U.S.A. 105, 13252-13257. doi: 10.1073/pnas.0805721105

Miller, D., Summers, J., and Silber, S. (2004). Environmental versus genetic sex determination: a possible factor in dinosaur extinction? Fertil. Steril. 81, 954-964. doi: 10.1016/j.fertnstert.2003.09.051

Mitchell, N. J., Allendorf, F. W., Keall, S. N., Daugherty, C. H., and Nelson, N. J. (2010). Demographic effects of temperature-dependent sex determination: will tuatara survive global warming? Global Change Biol. 16, 60-72. doi: 10.1111/j. 1365-2486.2009.01964.x

Mitchell, N. J., and Janzen, F. J. (2010). Temperature-dependent sex determination and contemporary climate change. Sex. Dev. 4, 129-140. doi: 10.1159/0002 82494

Mrosovsky, N. (1994). Sex ratios of sea turtles. J. Exp. Zool. 270, 16-27. doi: 10.1002/jez.1402700104

Mrosovsky, N., Hopkins-Murphy, S. R., and Richardson, J. I. (1984). Sex ratio of sea turtles - seasonal changes. Science 225, 739-741. doi: 10.1126/science.225.4663.739

Mrosovsky, N., and Provancha, J. (1992). Sex ratio of hatchling loggerhead sea turtles - data and estimates from a 5-year study. Can. J. Zool. 70, 530-538. doi: 10.1139/z92-080

Nevoux, M., Weimerskirch, H., and Barbraud, C. (2007). Environmental variation and experience-related differences in the demography of the long-lived blackbrowed albatross. J. Anim. Ecol. 76, 159-167. doi: 10.1111/j.1365-2656.2006. 01191.x

Parmesan, C., and Yohe, G. (2003). A globally coherent fingerprint of climate change impacts across natural systems. Nature 421, 37-42. doi: 10.1038/nature 01286

Patino-Martinez, J., Marco, A., Quinones, L., and Hawkes, L. A. (2012). A potential tool to mitigate the impacts of climate change to the Caribbean leatherback sea turtle. Global Change Biol. 18, 401-411. doi: 10.1111/j.1365-2486.2011.02532.x

Pen, I., Uller, T., Feldmeyer, B., Hards, A., While, G. M., and Wapstra, E. (2010). Climate-driven population divergence in sex-determining systems. Nature 468, 436-438. doi: 10.1038/nature09512

Pinsky, M. L., Worm, B., Fogarty, M. L., Sarmiento, J. L., and Levin, S. A. (2013). Marine taxa track local climate velocities. Science 341, 1239-1242. doi: 10.1126/ science. 1239352

Poloczanska, E. S., Limpus, C. J., and Hays, G. C. (2009). Vulnerability of marine turtles to climate change. Adv. Mar. Biol. 56, 151-211. doi: 10.1016/S0065-2881 (09)56002-6

Schofield, G., Dimadi, A., Fossette, S., Katselidis, K. A., Koutsoubas, D., Lilley, M. K. S., et al. (2013a). Satellite tracking large numbers of individuals to infer population level dispersal and core areas for the protection of an endangered species. Divers. Distrib. 19, 834-844. doi: 10.1111/ddi.12077 
Schofield, G., Hobson, V. J., Fossette, S., Lilley, M. K. S., Katselidis, K. A., and Hays, G. C. (2010). Fidelity to foraging sites, consistency of migration routes and habitat modulation of home range by sea turtles. Diversity Distrib. 16, 840-853. doi: 10.1111/j.1472-4642.2010.00694.x

Schofield, G., Scott, R., Dimadi, A., Fossette, S., Katselidis, K. A., Koutsoubas, D., et al. (2013b). Evidence-based marine protected area planning for a highly mobile endangered marine vertebrate. Biol. Conserv. 161, 101-109. doi: 10.1016/ j.biocon.2013.03.004

Schofield, G., Katselidis, K. A., Pantis, J. D., Dimopoulos, P., and Hays, G. C. (2006). Behaviour analysis of the loggerhead sea turtle (Caretta caretta) from direct inwater observation. Endang. Spec. Res. 2, 71-79. doi: 10.3354/esr002071

Southwood, A., and Avens, L. (2010). Physiological, behavioral, and ecological aspects of migration in reptiles. J. Comp. Physiol. B 180, 1-23. doi: 10.1007/ s00360-009-0415-8

Tucker, A. D. (2010). Nest site fidelity and clutch frequency of loggerhead turtles are better elucidated by satellite telemetry than by nocturnal tagging efforts: implications for stock estimation. J. Exp. Mar. Biol. Ecol. 383, 48-55. doi: 10.1016/j. jembe.2009.11.009

van Dam, R. P., Diez, C. E., Balazs, G. H., Colon Colon, L. A., McMillan, W. O., and Schroeder, B. (2008). Sex-specific migration patterns of hawksbill turtles from Mona Island, Puerto Rico. Endang. Spec. Res. 4, 85-94. doi: 10.3354/esr00044

Warner, D. A., and Shine, R. (2008). The adaptive significance of temperaturedependent sex determination in a reptile. Nature 451, 566-568. doi: 10.1038/ nature06519

Weber, N., Weber, S. B., Godley, B. J., Ellick, J., Witt, M., and Broderick, A. C. (2013). Telemetry as a tool for improving estimates of marine turtle abundance. Biol. Conserv. 167, 90-96. doi: 10.1016/j.biocon.2013.07.030

Witt, M. J., Hawkes, L. A., Godfrey, M. H., Godley, B. J., and Broderick, A. C. (2010). Predicting the impacts of climate change on a globally distributed species: the case of the loggerhead turtle. J. Exp. Biol. 213, 901-911. doi: 10.1242/jeb.038133
Wood, A., Booth, D. T., and Limpus, C. J. (2013). Sun exposure, nest temperature and loggerhead turtle hatchlings: implications for beach shading management strategies at sea turtle rookeries. J. Exp. Biol. Ecol. 451, 105-115. doi: 10.1016/j.jembe.2013.11.005

Wright, L. I., Stokes, K. L., Fuller, W. J., Godley, B. J., McGowan, A., Snape, R., et al. (2012). Turtle mating patterns buffer against disruptive effects of climate change. Proc. Biol. Sci. 279, 2122-2127. doi: 10.1098/rspb. 2011.2285

Zbinden, J. A., Bearhop, S., Bradshaw, P., Gill, B., Margaritoulis, D., Newton, J., et al. (2011). Migratory dichotomy and associated phenotypic variation in marine turtles revealed by satellite tracking and stable isotope analysis. Mar. Ecol. Prog. Ser. 421, 291-302. doi: 10.3354/meps08871

Conflict of Interest Statement: The authors declare that the research was conducted in the absence of any commercial or financial relationships that could be construed as a potential conflict of interest.

Received: 20 August 2014; paper pending published: 02 September 2014; accepted: 04 September 2014; published online: 19 September 2014.

Citation: Hays GC, Mazaris AD and Schofield G (2014) Different male vs. female breeding periodicity helps mitigate offspring sex ratio skews in sea turtles. Front. Mar. Sci. 1:43. doi: 10.3389/fmars.2014.00043

This article was submitted to Marine Megafauna, a section of the journal Frontiers in Marine Science.

Copyright () 2014 Hays, Mazaris and Schofield. This is an open-access article distributed under the terms of the Creative Commons Attribution License (CC BY). The use, distribution or reproduction in other forums is permitted, provided the original author(s) or licensor are credited and that the original publication in this journal is cited, in accordance with accepted academic practice. No use, distribution or reproduction is permitted which does not comply with these terms. 